\title{
Cognitive function during early childhood did not improve with declining blood lead concentrations
}

\author{
Tong S, Baghurst PA, Sawyer MG, et al. Declining blood lead levels and changes in cognitive function during childhood. The Port \\ Pirie cohort study. JAMA 1998 Dec 9;280:1915-9.
}

\section{Question}

Are declining blood lead concentrations associated with changes in cognitive function during childhood?

\section{Design}

Cohort study with follow up from birth to 11-13 years of age.

\section{Setting}

Urban and rural communities surrounding a large lead smelter in Post Pirie, South Australia.

\section{Participants}

375 children born between $1979-82$, and evaluated at 11-13 years of age.

\section{Assessment of risk factors}

Venous blood samples to assess lead concentrations were collected from the mother before birth, from the umbilical cord at birth, and from each child at age 6, 15, and 24 months and annually thereafter until age 7 years, and then again at age 11-13 years. At each blood sampling, information was obtained on a wide range of psychosocial, demographic, environmental, and biomedical factors.

\section{Main outcome measures}

Children's cognitive development assessed by interviewers unaware of the children's exposure and developmental histories using the Bayley Mental Development Index at 2 years of age, the McCarthy General Cognitive Index at 4 years of age, and IQs from the Wechsler Intelligence Scale (revised version) at 7 and 11-13 years of age.

\begin{abstract}
Main results
After adjustment for confounding variables, there was an inverse association between blood lead concentration and cognitive development at all ages (ie, higher lead concentrations were associated with lower cognitive function). Mean blood lead concentrations in children decreased from $1.02 \mu \mathrm{mol} / \mathrm{l}(21.2 \mu \mathrm{g} / \mathrm{dl})$ at 2 years of age to $0.38 \mu \mathrm{mol} / \mathrm{l}(7.9 \mu \mathrm{g} / \mathrm{dl})$ at $11-13$ years of age. Cognitive scores in children whose blood lead concentration declined most were generally not improved relative to the scores of children whose blood lead concentrations declined least (table). The analysis showed that compared with children with lower exposure levels, the cognitive deficit in the group with higher exposure changed little with age, even though blood lead concentrations declined substantially after 2 years of age.
\end{abstract}

\section{Conclusion}

Cognitive function during early childhood did not improve with declining blood lead concentrations.

Changes in blood lead concentration and children's IQ between 7 and 11-13 years of age

$\left.\begin{array}{lll}\hline \begin{array}{l}\text { Decline in blood lead } \\
\text { concentrations, } \mu \text { mol/ }(\mu \mathrm{g} / \mathrm{dl})\end{array} & \begin{array}{l}\text { Change in IQ points, mean } \\
(95 \% \mathrm{CI})\end{array} & p \text { Value* } \\
\hline<0.11(<2.3) & -5.4(-3.8 \text { to }-7.0) \\
0.11 \text { to } 0.24(2.3 \text { to } 4.9) & -5.0(-3.2 \text { to }-6.8) \\
>0.24(>4.9) & -3.8(-2.3 \text { to }-5.3)\end{array}\right\} \quad$\begin{tabular}{l}
0 \\
\hline
\end{tabular}

*p value calculated using analysis of variance.

Sources of funding: National Health and Medical Research Council, Canberra, Australia and the Channel 7 Children's Research Foundation.

For correspondence:Dr S Tong, MBBS, PhD, Centre for Public Health Research, Queensland University of Technology, Brisbane, Queensland 4059, Australia. Fax +61 738643369.

\section{Commentary}

This study by Tong et al may be thought of as a second generation longitudinal study of the effects of lead exposure on cognitive functioning. First generation longitudinal studies showed that at low levels of exposure, lead was associated with reductions in intellectual functioning in children after controlling for confounding factors. ${ }^{1}$ After a decade of research, the findings of these first generation studies have led to a growing consensus that at even low levels of exposure (eg, $10 \mu \mathrm{g} / \mathrm{dl}$ blood lead concentration), lead may have small but detectable effects on cognitive ability and academic achievement. Second generation studies have begun to concentrate on the effects of lead exposure on cognitive functioning over the life course and have established that the effects appear to extend into adolescence and young adulthood..$^{2-4}$
Tong et al's study shows that subsequent reductions in lead concentrations do not ameliorate the effects of early lead exposures fully. Their findings clearly raise the possibility that the cognitive effects of early lead exposure are largely irreversible. Although the study is not immune to the threats to validity (eg, confounding, measurement error, sample selection bias), it makes an important contribution in showing how low level lead exposure may influence cognitive functioning over the life course.

It is important to recognise that studies in this area have been conducted in a changing environmental and political context. First generation studies conducted in the 1980s contained large numbers of participants with clearly raised lead concentrations. However, awareness of the potentially harmful effects of lead exposure has led to a decline in population lead concentrations. In effect, Tong et al have capitalised on this natural experiment. Tong et al's study raises the possibility that the effects of early lead exposure may be largely irreversible, and emphasises the continued need to minimise the exposure of young children to the potentially damaging effects of lead.

David M Fergusson, $\mathrm{PhD}$ Christchurch School of Medicine Christchurch, New Zealand

\footnotetext{
1 Fulton M, Raab G, Thomson G, et al. Lancet 1987;1:1221-6.

2 Needleman HL, Schell A, Bellinger D, et al. $N$ Engl J Med 1990;322:83-8.

3 Fergusson DM, Horwood LJ, Lynskey MT. $J$ Child Psychol Psychiatry 1993;34:215-27.

4 Fergusson DM, Horwood LJ, Lynskey MT. J Child Psychol Psychiatry 1997;38:471-8.
} 